\title{
Kinetics of Eucalypt Lignosulfonate Oxidation to Aromatic Aldehydes by Oxygen in Alkaline Medium
}

\author{
Sonia G. Santos, Ana P. Marques, Diana L. D. Lima, Dmitry V. Evtuguin,* and \\ Valdemar I. Esteves \\ CICECO and CESAM/Department of Chemistry, University of Aveiro, Portugal 3810-193
}

\begin{abstract}
The oxidation kinetics of lignosulfonates (LS) from acidic magnesium-based sulfite pulping of Eucalyptus globulus wood with oxygen under alkaline conditions was studied. The analysis of oxidation products in the reaction system $\mathrm{O}_{2} / \mathrm{NaOH}$ revealed a predominance of aromatic aldehydes (vanillin and syringic aldehyde) though small amounts of vanillic and syringic acids and acetophenone/phenylacetaldehyde derivatives have also been detected. The rate constant of syringic aldehyde formation was roughly twice of that for vanillin. The effective activation energies for the oxidation of LS to aromatic aldehydes (ca. $60-70 \mathrm{~kJ} / \mathrm{mol}$ ) were rather different to those found for the formation of aromatic acids (ca. $110 \mathrm{~kJ} / \mathrm{mol}$ ) indicating different mechanisms involved in the rate-determining reaction step. The addition of catalyst (copper salt, $20 \% \mathrm{w} / \mathrm{w}$ ) promoted the LS oxidation with increments of aromatic aldehyde yields by $25-50 \%$. The maximum yields of syringic aldehyde and vanillin upon LS oxidation were 16.1 and $4.5 \%$, respectively $\left(150{ }^{\circ} \mathrm{C}, 20 \mathrm{~min}, P_{\mathrm{O}_{2}}\right.$ $=10$ bar, $0.9 \mathrm{M} \mathrm{NaOH}$ solution). The highly negative effect of concomitant sugars in sulfite liquor to the yield of aromatic aldehydes was highlighted.
\end{abstract}

\section{Introduction}

Acid sulfite pulping of wood is a conventional industrial process of cellulosic pulp production for chemical and papermaking needs. ${ }^{1}$ Free and base-combined sulfur dioxide is used as reagent providing the depolymerization and dissolution of lignin from wood thus allowing the liberation of pulp fibers. Lignosulfonates (LS) are sulfonated lignin-derived byproducts in the composition of sulfite spent liquors (SLs) that are separated from cellulosic pulp after the wood cooking. SLs, after their concentration by evaporation, are usually burned for the inorganic base and energy recovery. ${ }^{1}$ If the nonregenerable base is used for the cooking (e.g., calcium-based) the concentrated liquor must be utilized since it cannot be discharged to natural basins due to environmental concerns. SLs are recognized valuable raw material for the production of phenolics, polymer formulations, adhesives, ethanol, single cell proteins, etc. ${ }^{2-4} \mathrm{LS}$ in SLs may be used without chemical modification in concretes, drilling oils, etc. or chemically modified to produce fine chemicals. ${ }^{4,5}$ The oxidation of LS by molecular oxygen in alkaline media to produce vanillin is the only process implemented on an industrial scale since 1930s-1940s. ${ }^{6}$

Historically, sulfite pulping involved primary the spruce wood (softwood), in which lignin is constituted essentially by guaiacyl structural units (Figure 1). Therefore, the oxidation of LS gave vanillin as a major product. Vanillin is an important flavor $^{5}$ and valuable raw-material for the production of fine chemicals/ pharmaceutics, adhesives, and polymers. ${ }^{5-8}$ The oxidation of LS from hardwood (beech, eucalypt, aspen, etc.) is much less studied than oxidation of LS from softwood and practically not explored. Since hardwood lignin is constituted predominantly by syringyl structural units (Figure 1), the oxidation of corresponding LS gives rise mainly to syringyl aldehyde, besides vanillin. ${ }^{6}$ Interest has increased recently in aromatic aldehydes derived from technical lignins as a biorefinary concept invoked to diminish the dependence of modern economies from fossil resources.

* To whom correspondence should be addressed. Tel. +351 234 401526. Fax: +351 234 370084. E-mail: Dmitrye@ua.pt.
The yield of vanillin from the LS plays a decisive role on the economics of production and generally does not exceed $4-8 \% .^{2-6,9,10}$ The use of oxidation catalysts (mainly salts of transition metals) allows the increment of the yield up to $6-12 \%{ }^{4,10}$ However, the additional steps for the vanillin purification are required to comply with the restrictions of the food industry in relation to heavy metal content. The understanding of LS degradation with oxygen under strong alkaline conditions is crucial to improve the production of aromatic aldehydes from SLs.

Despite of numerous studies on mechanisms of the oxidative cleavage of LS to aromatic aldehydes this subject is far from being completely understood. ${ }^{4,11}$ The complex structure of LS hinders the rationalization of the oxidation mechanism to improve the aromatic aldehyde yield. Nevertheless it is commonly accepted that LS degradation comprises alkaline hydrolysis and autoxidation steps. ${ }^{4,6,9-13}$ The alkaline hydrolysis at $\mathrm{pH} \geq 11$ includes the retro-aldol cleavage of benzyl alcoholtype structures containing $\gamma$-carbonyl groups ${ }^{11,12}$ and cleavage
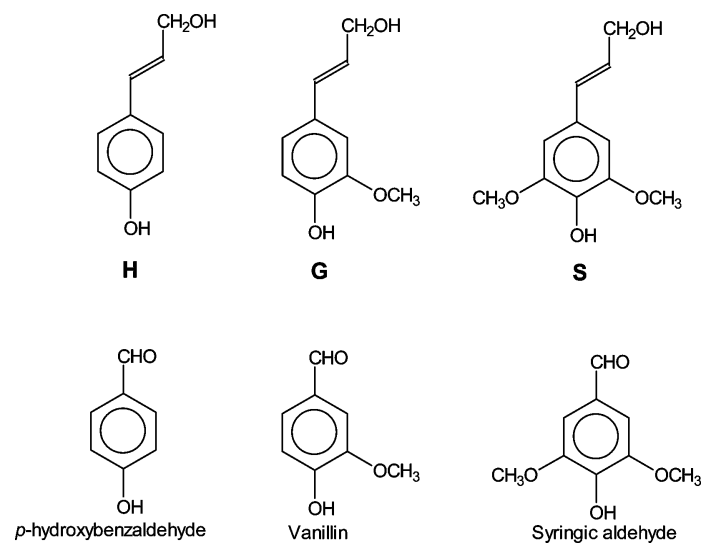

Figure 1. Lignin precursors symbolizing different structural units (cinnamyl $(\mathbf{H})$, coniferyl (G), and sinapyl (S) alcohols). Coniferous lignins are built essentially by $\mathbf{G}$-type structures with a small proportion of $\mathbf{H}$-type units, whereas deciduous lignins are of $\mathbf{S} / \mathbf{G}$-type with a small proportion of $\mathbf{H}$-type units. The aromatic aldehydes arisen in lignin oxidation are depicted below. 
of $\alpha$-sulfonated $\beta-O-4$ structures ${ }^{13}$ leading to vanillin formation. The yield of aromatic aldehydes, however, increases by a factor $3-10$, while introducing the molecular oxygen in the reaction system. ${ }^{14,15}$ The $\mathrm{C}_{\alpha}-\mathrm{C}_{\beta}$ oxidative cleavage of the propane chain in the LS structural units, the main reaction pathway leading to formation of aromatic aldehydes, proceeds under alkaline conditions only $(\mathrm{pH}>10)$. The role of base consists in the partial desulfonation of LS with formation of unsaturated $\mathrm{C}_{\alpha}-\mathrm{C}_{\beta}$ moieties (enol-, stilbene-, and diene-type structures) and ionization of phenoxyls, thus reducing the energetic barrier in reaction with oxygen. ${ }^{10,11,14,15}$ The yield of aromatic aldehydes is affected by their further oxidation into low-molecular weight products and by condensation via radical coupling. ${ }^{15}$

The market of eucalypt sulfite SLs in South Europe (Portugal and Spain) and in South Africa, where the production of dissolving- and paper-grade sulfite pulps reaches about one million tons per year, is rather significant. Therefore the potential of eucalypt LS for the production of aromatic aldehydes deserves attention. Recent studies revealed that the structural features of eucalypt LS are rather different from those commonly reported for softwood LS, with respect to the molecular weight, chemical structure, and the amount of monomeric sulfonated products. ${ }^{16,17}$ The response of eucalypt LS to oxidation with oxygen in alkaline media is not assessed yet.

The main goal of this work was the study of eucalypt LS oxidation to aromatic aldehydes with molecular oxygen in sodium hydroxide solution. The major oxidation products were identified by gas chromatography coupled with mass spectrometry detector (GC-MS), and the kinetics of their formation in the temperature range of $130-150{ }^{\circ} \mathrm{C}$ was monitored using capillary zone electrophoresis (CZE). The parameters of kinetic equations were interpreted in terms of oxidation mechanisms involved and the composition of LS.

\section{Materials and Methods}

Materials. Industrial thin (diluted) and thick (concentrated) liquors from magnesium-based acidic sulfite pulping of Eucalyptus globulus were supplied by Caima-Indústria de Celulose SA (Constância, Portugal). For a series of oxidation experiments, thin and thick liquors were purified by dialysis with partially benzoylated cellophane membranes (2000 nominal molecular weight cut-off (NMWCO) for thick and 5000 NMWCO for thin liquors) against distilled water during $8 \mathrm{~h}$ followed by a freezedrying of the dialysate. ${ }^{16,17}$ Thin liquor without purification (SSL) was also used after freeze-drying. SSL contained $27 \%$ of sugars (mainly xylose) and $18 \%$ of ash, whereas purified thin liquor (PSSL) contained only $5 \%$ of sugars and $6 \%$ of ash. The purified thick liquor (PTHSL) contained intermediate amounts of sugars and ash (8\% each). ${ }^{17}$ The $\mathbf{S : G}$ (proportion of syringyl to guaiacyl units) molar ratio in LS of all samples varied from 71:29 in PSSL to 81:19 in PTHSL and SSL. ${ }^{17}$ The $\mathrm{S} / \mathrm{C}_{9}$ molar ratio for the SSL, PSSL, and PTHSL samples were of $0.78,0.45$, and 0.77 , respectively.

Experimental Procedures. Typically, $500 \mathrm{mg}$ of dry LS sample was dissolved in $100 \mathrm{~mL}$ of $\mathrm{NaOH}$ solution and placed in the Teflon beaker of the stainless reactor PARR model 4843 $(0.25 \mathrm{~L})$ equipped with an automatic temperature control system, pressure control, and mechanical stirring ( $\sim 250 \mathrm{rpm})$. Timeto-temperature period was around $15 \mathrm{~min}$ and this moment considered as a starting point of reaction. The reactor was equipped by a sampling line to assess the reaction mixture.

Analyses. The identification of reaction products, isolated by $3 \times 100 \mathrm{~mL}$ extraction with $\mathrm{CHCl}_{3}$ of acidified to $\mathrm{pH} 2$ reaction mixture was carried out by GC-MS as trimethylsilyl (TMS)
Table 1. Oxidation Products of Eucalypt Lignosulfonates

\begin{tabular}{lc}
\multicolumn{1}{c}{ oxidation product } & $\begin{array}{c}\text { yield, \% of } \\
\text { lignosulfonate }\end{array}$ \\
\hline $\begin{array}{l}\text { 4-hydroxy-3-methoxybenzaldehyde (vanillin) } \\
\text { 4-hydroxy-3-methoxyacetophenone }\end{array}$ & 3.0 \\
$\begin{array}{l}\text { (acetoguaiacone) } \\
\text { 4-hydroxy-3,5-dimethoxybenzaldehyde } \\
\text { (syringic aldehyde) }\end{array}$ & 0.6 \\
2-(4-hydroxy-3-methoxyphenyl)acetaldehyde & 7.3 \\
4-hydroxy-3-methoxybenzoic acid (vanillic acid) & 0.2 \\
2-(4-hydroxy-3,5-dimethoxyphenyl)acetaldehyde & 1.4 \\
4-hydroxy-3,5-dimethoxybenzoic acid (syringic acid) & 0.5 \\
\end{tabular}

derivatives. About $10 \mathrm{mg}$ of dry sample (chloroform extract) was dissolved in $300 \mu \mathrm{L}$ of pyridine followed by addition of silylation reagents (50 $\mu \mathrm{L}$ of TMSC (trimethylsilyl chloride) and $250 \mu \mathrm{L}$ of BSTFA (,$O$-bis(trimethylsilyl)trifluoroacetamide) in a Sovirel tube. The reaction mixture was heated at $80{ }^{\circ} \mathrm{C}$ for $1 \mathrm{~h}$. The derivatized reaction products were injected ( $1 \mu \mathrm{L}$ ) into Trace Gas Chromatograph 2000 Series equipped by Finnigan Trace MS detector using DB-1 column (J\&W, $30 \mathrm{~m}$ length and $0.32 \mathrm{~mm}$ i.d. with $0.25 \mathrm{~mm}$ film thickness) and helium as a carrier gas $(35 \mathrm{~cm} / \mathrm{s})$. The chromatographic conditions were as follows: initial temperature, $140{ }^{\circ} \mathrm{C}$; temperature gradient, $5 \% \mathrm{~min}$; final temperature, $270{ }^{\circ} \mathrm{C}$; time at final temperature, $10 \mathrm{~min}$; injector temperature, $230{ }^{\circ} \mathrm{C}$, interface temperature, $270{ }^{\circ} \mathrm{C}$. The identification of detected compounds was carried out using NIST database (version 2.0).

In the kinetic studies the reaction mixture from LS oxidation was directly analyzed by capillary zone electrophoresis (CZE). All experiments were carried out on a Beckman P/ACE MDQ capillary electrophoresis system equipped with a diode array detector tuned at $\lambda=214 \mathrm{~nm}$. Separation was carried out on a $50.0 \mathrm{~cm}$ long fused-silica capillary $(40.0 \mathrm{~cm}$ effective length to the detector) and $75 \mu \mathrm{m}$ internal diameter. The run buffer consisted of a daily prepared $4.3 \times 10^{-2} \mathrm{M} \mathrm{Na}_{2} \mathrm{~B}_{4} \mathrm{O}_{7}+2.7 \times$ $10^{-2} \mathrm{M} \mathrm{KH}_{2} \mathrm{PO}_{4}+8.5 \% \mathrm{CH}_{3} \mathrm{CN}$ solution with a final $\mathrm{pH}$ of 9.15. Injection time was $3 \mathrm{~s}$ with a pressure of 0.3 psi. Electrophoretic separations were carried out at a positive power supply of $25 \mathrm{kV}$ for $15 \mathrm{~min}$, maintaining the capillary temperature at $25{ }^{\circ} \mathrm{C}$ resulting in a current of $\sim 250 \mu \mathrm{A}$. Ethylvanillin $\left(2 \times 10^{-4} \mathrm{M}\right)$ was used as an internal standard.

\section{Results and Discussion}

Oxidation Products. The analysis of oxidation products in reaction system $\mathrm{O}_{2} / \mathrm{NaOH}$ have been carried out using an industrial thick liquor from acidic magnesium-based sulfite pulping of Eucalyptus globulus wood purified by dialysis. The purification of thick liquor with a 2000 NMWCO benzoylated cellophane membrane allows the elimination of inorganic salts, a significant part of monosugars, and low-molecular wood degradation products (acetic acid, furfural, pyrogallol, etc.) without changing the original composition of the LS. ${ }^{17}$ The purity of LS increased from ca. 58\% to ca. $84 \%$ after purification by dialysis. The purified liquor (PTHSL) was freeze-dried and used in the oxidation experiments under the following conditions: temperature, $160{ }^{\circ} \mathrm{C}$; reaction time, $10 \mathrm{~min} ; 1.0 \%(\mathrm{w} / \mathrm{w})$ PTHSL; $0.75 \mathrm{M} \mathrm{NaOH}$; oxygen pressure 6 bar.

The composition of aromatic oxidation products, isolated from reaction mixture by extraction with chloroform, was assessed by GC-MS (Table 1). About $95 \%$ of monomeric aromatic compounds have been identified. The most abundant products with total yield of about $12 \%$ (based on LS) were those that arose from $\mathrm{C}_{\alpha}-\mathrm{C}_{\beta}$ cleavage of the propane chain: vanillin, syringic aldehyde, vanillic, and syringic acids. However, a small 

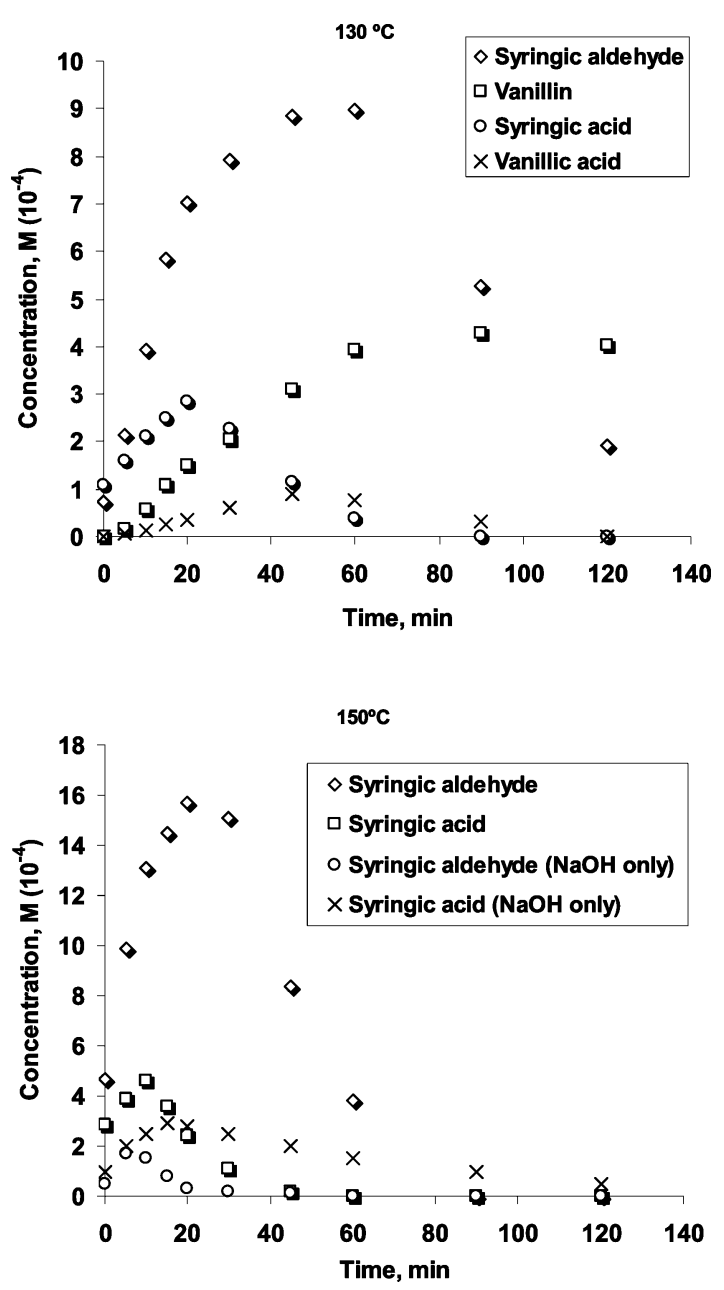

Figure 2. Typical profiles of LS oxidation products at $130{ }^{\circ} \mathrm{C}$ (top panel). The profiles of syringic aldehyde and syringic acid at $150{ }^{\circ} \mathrm{C}$ under aerobic conditions $\left(P_{\mathrm{O}_{2}}=6 \mathrm{bar} ; C_{\mathrm{NaOH}}=0.75 \mathrm{M}\right)$ and under nitrogen atmosphere $(\mathrm{NaOH}$ only) are depicted in the bottom panel.

amount of $\mathrm{C}_{\beta}-\mathrm{C}_{\gamma}$ cleavage products have been also detected: acetoguaiacone and aromatic acetaldehydes (Table 1). The detected aromatic aldehydes and acids in the presence of internal standard (ethylvanillin) were used for the calibration of electropherograms used in CZE analysis of LS oxidates. This allowed monitoring of LS oxidation via direct analysis of dissolved products in oxidates without their previous isolation and derivatization.

Kinetics of Lignosulfonate Oxidation. The kinetics of formation of the major aromatic products (vanillin, syringic aldehyde, vanillic, and syringic acids) during oxidation of PTHSL have been carried out in $0.75 \mathrm{M} \mathrm{NaOH}$ solution ( $\mathrm{pH}$ 13.1) at the temperature interval of $130-150{ }^{\circ} \mathrm{C}$ and the oxygen pressure of 6 bar. These conditions have guarantied pseudoconstant alkalinity and the oxygen supply along all periods of LS oxidation.

The typical profiles of oxidation products are presented in Figure 2. The concentrations of aromatic aldehydes and acids reached maximum followed by accentuated decrease of their contents in oxidates. This behavior was due to the subsequent degradation of aforementioned aromatic products. ${ }^{11,15}$ The yield of aromatic aldehydes was clearly predominant over corresponding acids (3-4 times higher). Moreover, the formation rate of syringic aldehyde (SA) was 6-8 times higher than vanillin (VA) at low reaction times though the proportion of $\mathbf{S}$ to $\mathbf{G}$ structural units in LS did not exceed 4.3. Furthermore, $\mathrm{SA} / \mathrm{VA}$ ratios decreased to around $2-2.5$ to the reaction times
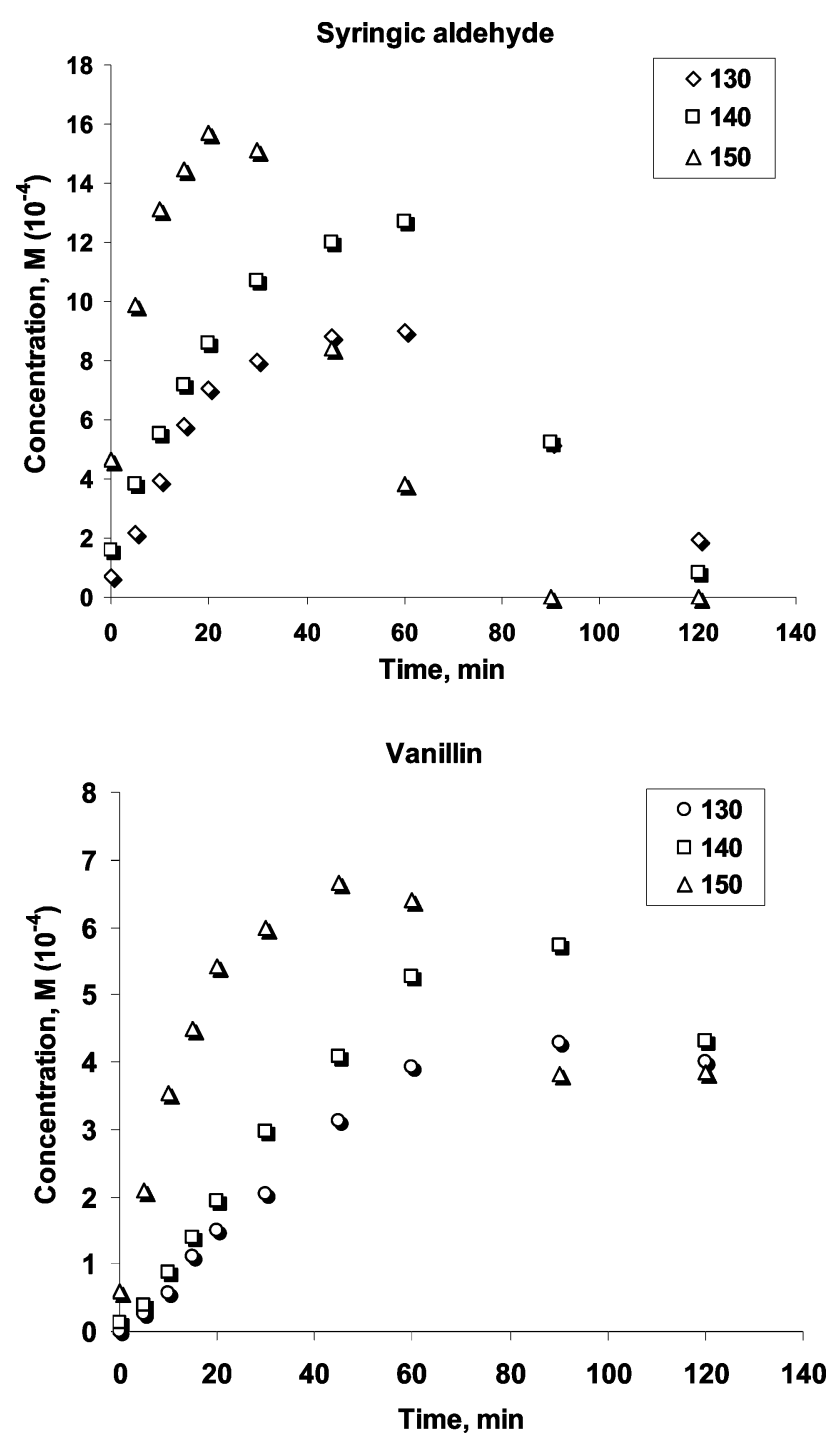

Figure 3. Profiles of aromatic aldehydes in LS oxidation by oxygen at $130-150{ }^{\circ} \mathrm{C}\left(P_{\mathrm{O}_{2}}=6\right.$ bar; $\left.C_{\mathrm{NaOH}}=0.75 \mathrm{M}\right)$.

corresponding to a maximum yield of aromatic aldehydes. (Figures 2 and 3). The reaction times relating to the maximum yield of aromatic aldehydes were systematically shorter for SA than for VA. These features may be interpreted in terms of the relative oxidation rate of $\mathbf{S}$ - and $\mathbf{G}$-type units in LS and the extent of secondary reactions of aromatic aldehydes. Thus, the oxidation of $\mathbf{S}$ units in LS is much faster than of $\mathbf{G}$ units and SA suffers stronger subsequent degradation than VA. This statement is evidenced from the faster drop of SA concentration when compared to the concentration of VA (Figures 2, 3). A very rough estimation of the relative degradation rates of SA and VA $\left(r=v_{\mathrm{SA}}^{\mathrm{d}} / v_{\mathrm{VA}}^{\mathrm{d}}\right)$, assessed via the incline of aldehyde concentration profiles $(\Delta C / \Delta t)$ just below the maximum concentration point $\left(t_{\max }\right)$, revealed the $r$ values about 5 . These conclusions are in agreement with the knowledge of higher reactivity of $\mathbf{S}$-type than of $\mathbf{G}$-type lignin units in reactions with oxygen in alkaline media. ${ }^{6,18}$ In addition, the stability of SA in the reaction system $\mathrm{O}_{2} / \mathrm{NaOH}$ was suggested to be much lower than for VA. ${ }^{15}$

The contribution of homolytic and heterolytic reactions to the formation of aromatic aldehydes and acids was estimated by LS treatment in $\mathrm{NaOH}$ solution under oxygen and nitrogen atmospheres at $150{ }^{\circ} \mathrm{C}$ (Figure 2). The yield of SA was highly sensitive to the presence of oxygen thus confirming the 
importance of homolytic reactions in formation of SA. On the contrary, the yield of syringic acid (SAC) did not show the same behavior (the difference between aerobic and anaerobic trials was less pronounced than for SA) indicating the eventual contribution of heterolytic reactions. Under anaerobic conditions the concentration of SA increased and dropped quickly while the concentration of SAC simultaneously increased showing the maximum at slightly longer reaction times (Figure 2). It may be proposed that at least part of SAC could be formed from SA via the base-promoted disproportionation reaction (Canizarro reaction). Hence the formation of SAC takes place not only via oxidation pathways, as reported previously, ${ }^{15}$ but also via alkalicatalyzed reactions.

The yields of aromatic aldehydes under LS oxidation in alkaline medium were always increased with the increased reaction temperature (Figure 3 ). Simultaneously the maxima of these yields emerged to shorter reaction times while the temperature rose. However, the oxidation of LS at temperatures higher than $150{ }^{\circ} \mathrm{C}$ was too fast and hindered the assessment of kinetics of SA formation. Thus, during LS oxidation at 160 ${ }^{\circ} \mathrm{C}$ the maximum yield of SA was detected at less than $5 \mathrm{~min}$.

The effective kinetic parameters have been evaluated considering the oxidation of LS as a consecutive reaction, where the oxidation products $(\mathrm{P})$ suffer further degradation with the formation of low-molecular weight products (D):

$$
\mathrm{LS} \stackrel{k_{1}\left(\mathrm{O}_{2}, \mathrm{OH}^{-}\right)}{\longrightarrow} \mathrm{P} \stackrel{k_{2}}{\longrightarrow} \mathrm{D}
$$

Since the oxidation of LS takes place under quasi-constant concentrations of base (sodium hydroxide) and oxygen, the reaction rate may be expressed as follow:

$$
\frac{\mathrm{d}[\mathrm{LS}]}{\mathrm{d} t}=-K_{\mathrm{obs}}[\mathrm{LS}]
$$

where $K_{\mathrm{obs}}=-\kappa\left[\mathrm{OH}^{-}\right]^{b}\left[\mathrm{O}_{2}\right]^{c}$. Taken into consideration that $r_{1}$ $\gg r_{2}\left(r_{1}\right.$ and $r_{2}$ are the formation rates of $\mathrm{P}$ and $\mathrm{D}$, respectively) and $(-\mathrm{d}[\mathrm{LS}] / \mathrm{d} t \approx \mathrm{d}[\mathrm{P}] / \mathrm{d} t)$, eq 2 may be rewritten as follows:

$$
\frac{\mathrm{d}[\mathrm{P}]}{\mathrm{d} t}=K_{\mathrm{obs}}[\mathrm{LS}]
$$

Since $[\mathrm{LS}]=\left[\mathrm{LS}_{0}\right]-[\mathrm{P}]\left(\left[\mathrm{LS}_{0}\right]\right.$ is the initial concentration of LS structures oxidized to aromatic aldehydes) and $\left[\mathrm{LS}_{0}\right] \approx\left[\mathrm{P}_{\infty}\right]$ $\left(\left[\mathrm{P}_{\infty}\right]\right.$ is the concentration of aromatic aldehydes at discontinuous reaction time, i.e., at $100 \%$ conversion of all reactive LS structures), eq 3 may be rewritten as follows:

$$
\frac{\mathrm{d}[\mathrm{P}]}{\mathrm{d} t}=K_{\mathrm{obs}}[\mathrm{P} \infty-\mathrm{P}]
$$

The integration of eq 4 allows the expression for linear dependence of $[\mathrm{P}]$ and the reaction time:

$$
\ln \left(\left[\mathrm{P}_{\infty}\right]-[\mathrm{P}]\right)=\ln \left[\mathrm{P}_{\infty}\right]-\mathrm{K}_{\mathrm{obs}} t
$$

The plot of $\ln \left(\left[\mathrm{P}_{\infty}\right]-[\mathrm{P}]\right)$ against the reaction time permitted the determination of the observed reaction constant $\left(K_{\text {obs }}\right)$. The $\left[\mathrm{P}_{\infty}\right]$ value corresponded to the $[\mathrm{P}]$ at maximum yield $\left(t=t_{\max }\right)$. Rather good linear correlations $\left(r^{2}=0.98-0.99\right)$ were observed for the relatively short reaction times $\left(t \leq t_{\max } / 2\right)$. The results on determination of $K_{\text {obs }}$ and effective activation energy $\left(E_{\mathrm{a}}\right)$ for aromatic aldehydes and acids in the temperature interval of 130- $150{ }^{\circ} \mathrm{C}$ are summarized in Table 2 .

The rate constants of LS oxidation to SA were two times higher than the rate constants of LS oxidation to VA. However,
Table 2. Effective Parameters of Formation of Aromatic Products in LS Oxidation

\begin{tabular}{lcccc}
\hline & syringic aldehyde & vanillin & syringic acid & vanillic acid \\
\hline \multicolumn{4}{l}{ Rate Constant for the Formation of Aromatic Product $\left(K_{\text {obs }} \times 10^{-3}\right), \mathrm{s}^{-1}$} \\
$130^{\circ} \mathrm{C}$ & 1.0 & 0.4 & 0.4 & 0.1 \\
$135^{\circ} \mathrm{C}$ & 1.2 & 0.5 & 0.7 & 0.2 \\
$140^{\circ} \mathrm{C}$ & 1.5 & 0.6 & 0.9 & 0.2 \\
$145^{\circ} \mathrm{C}$ & 1.9 & 0.8 & 1.4 & \\
$150^{\circ} \mathrm{C}$ & 2.4 & 1.1 & 1.9 & \\
\multicolumn{5}{c}{} \\
$E_{\mathrm{a}}$ & 62.6 & 70.5 & 108.0
\end{tabular}

$E_{\text {a }}$ values for both aldehydes were close each other and rather low. In effect, the same order of $E_{\mathrm{a}}$ was reported previously for the oxidation of different $\mathrm{kraft} / \mathrm{alkali}$ lignins to aromatic aldehydes under similar conditions. ${ }^{19,20}$ These values of $E_{\mathrm{a}}$ $(50-70 \mathrm{~kJ} / \mathrm{mol})$ are typical for the transformations where the rate-limiting stage is determined by homolytic reaction such as autoxidation with molecular oxygen. ${ }^{21,22}$ In contrast, the $E_{\text {a value }}$ in the oxidation of LS to SAC was relatively high $(108 \mathrm{~kJ} / \mathrm{mol})$ which is indicative to transformations where the rate-limiting step determined by heterolytic reaction. In effect, $E_{\text {a }}$ value calculated for the transfer of hydride ion from hydrate monoanion of aldehyde in alkali-promoted Cannizzaro reaction was appointed to $109 \mathrm{~kJ} / \mathrm{mol}^{23}$ The $E_{\mathrm{a}}$ value obtained for SAC (108 $\mathrm{kJ} / \mathrm{mol}$ ) is in tune with the previous discussion about the possible contribution of base-promoted disproportionation reactions to the formation of aromatic acids in LS oxidation under alkaline conditions.

Considering that $K_{\mathrm{obs}}=-\kappa\left[\mathrm{OH}^{-}\right]^{b}\left[\mathrm{O}_{2}\right]^{c}$, the effective orders of reactions leading to the formation of SA and VA were assessed from plots $\ln \left(K_{\text {obs }}\right)$ vs $\ln \left(C_{\mathrm{NaOH}}\right)$ and $\ln \left(K_{\text {obs }}\right)$ vs $\ln \left(P_{\mathrm{O}_{2}}\right)$ (Figures 4 and 5). It must be noted that the ionic strength of the reaction medium was not controlled in those experiments and the rate dependency revealed both the contributions from ionic strength and hydroxyl ion concentration. The content of aromatic aldehydes in LS oxidation was almost constant until the $\mathrm{NaOH}$ concentration of $0.5 \mathrm{M}$ (Figure 4). This result is explained by the alkali consumption with sulfonic groups in LS composition and by the appearance of acidic oxidation products, when the pseudoconstant alkali concentration in the reaction mixture could not be maintained. Therefore the dependence of $K_{\mathrm{obs}}$ from the alkali concentration was assessed in the interval of $0.5-0.9 \mathrm{M}$ for SA or in the interval of $0.6-0.9$ $\mathrm{M}$ for VA, where the linear correlation between $\ln \left(K_{\text {obs }}\right)$ and $\ln \left(C_{\mathrm{NaOH}}\right)$ was fulfilled (Figure 4$)$.

The reaction order in oxygen was found while oxidation trials were run in a pure oxygen atmosphere for pressures 2.0-10.0 bar, because in this interval a linear correlation between $\ln \left(K_{\mathrm{obs}}\right)$ and $\ln \left(P_{\mathrm{O}_{2}}\right)$ was observed (Figure 5). Similarly to that of alkali loads, the oxygen pressure below 2 bar was not enough to fulfill the condition of the pseudoconstant oxygen concentration during LS oxidation (insufficient amount of oxygen in reactor headspace). The oxygen concentration in solution was replaced by oxygen pressure since in the liquid phase at moderated pressures it is linearly proportional to the external pressure, as predicted by Henry's law $\left(\mathrm{CO}_{2} \sim \mathrm{PO}_{2}\right)$. Hence considering the emerged reaction orders in alkali (Figure 4 ) and in oxygen (Figure 5) and effective kinetic parameters (Table 2), the kinetics of formation of SA and VA may be described as follows:

$$
\frac{\mathrm{d}[\mathrm{SA}]}{\mathrm{d} t}=130000 \mathrm{e}^{62600 /(R T)}[\mathrm{LS}]^{1.0}\left[\mathrm{OH}^{-}\right]^{1.4}\left[\mathrm{O}_{2}\right]^{1.0}
$$



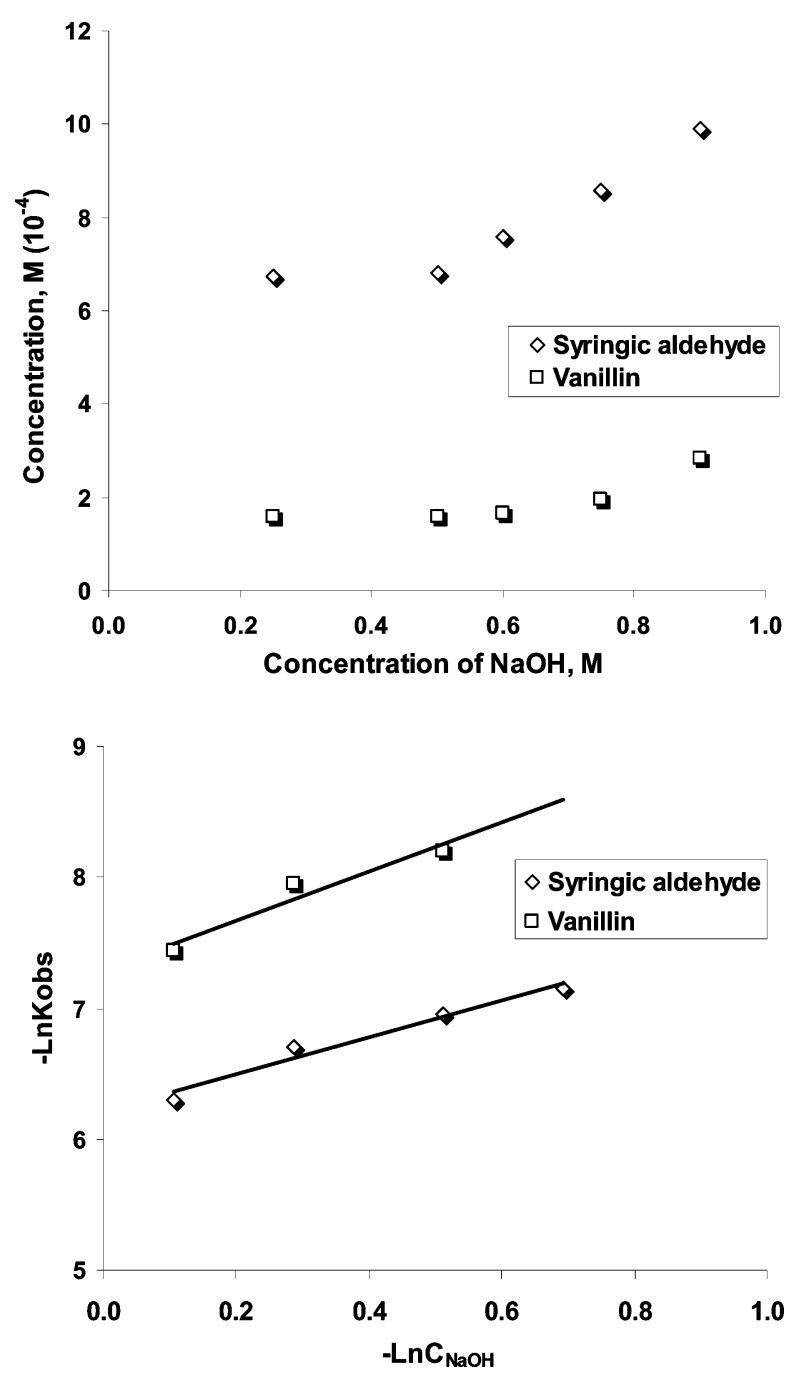

Figure 4. Effect of $\mathrm{NaOH}$ concentration on the yield of aromatic aldehydes in LS oxidation by oxygen $\left(140{ }^{\circ} \mathrm{C}, 20 \mathrm{~min}, P_{\mathrm{O}_{2}}=6 \mathrm{bar}\right)$. The reaction order in $\mathrm{NaOH}$ concentration $(b=1.4$ for syringic aldehyde and $b=1.9$ for vanillin) is assessed by analysis of plot $\ln \left(K_{\mathrm{obs}}\right)$ vs $\ln \left(C_{\mathrm{NaOH}}\right)$.

$$
\frac{\mathrm{d}[\mathrm{VA}]}{\mathrm{d} t}=540000 \mathrm{e}^{70500 /(R T)}[\mathrm{LS}]^{1.0}\left[\mathrm{OH}^{-}\right]^{1.9}\left[\mathrm{O}_{2}\right]^{1.0}
$$

The first order in LS and oxygen confirms the importance of bimolecular reactions in the rate-determining step such as the formation of hydroperoxides. ${ }^{21}$ Usually one-electron oxidation of phenolate with oxygen is considered a rate-limiting step in lignin oxidation. ${ }^{18,24-26}$ The simultaneous reaction of oneelectron oxidized substrate with oxygen, or with superoxide anion radical, leads to the formation of peroxides degraded according to conventional autoxidation mechanisms. The noninteger, higher than 1 reaction order in alkali concentration $\left(\left[\mathrm{OH}^{-}\right]\right)$indicates the simultaneous occurrence of numerous alkali-dependent reactions. This could be explained, at least partially, by the importance of desulfonation reactions leading to the formation of reactive with oxygen intermediates (units with unsaturated moieties in the propane chain). The formation of these structures is considered as a favorable step in lignin oxidation under alkaline conditions because of their lower first ionization potential when compared to lignin units with saturated moieties in a propane chain. ${ }^{25}$

The estimation of the activation entropy $\left(\Delta S^{\ddagger}\right)$ for the formation of SA and SAC has been carried out knowing the reaction frequency factors $A\left(1.3 \times 10^{5}\right.$ for SA and $6.56 \times$
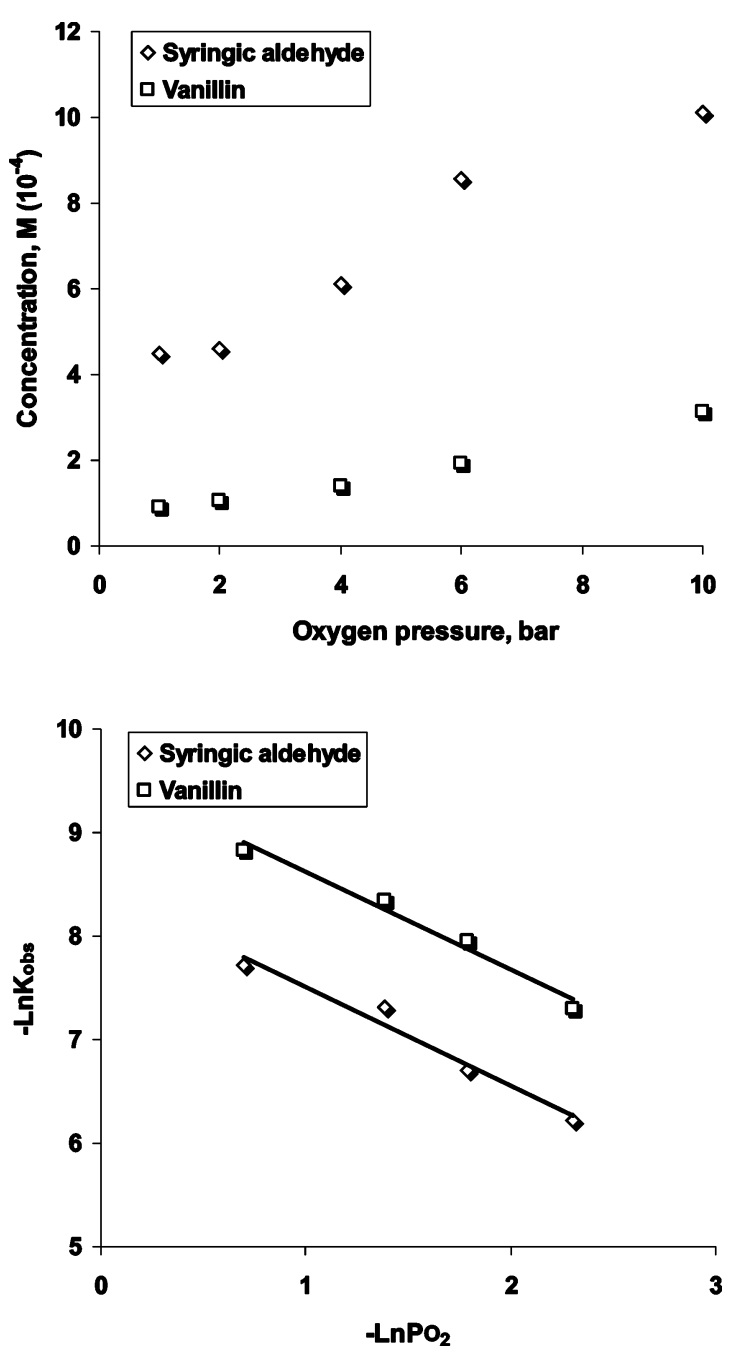

Figure 5. Effect of oxygen pressure concentration on the yield of aromatic aldehydes in LS oxidation $\left(140{ }^{\circ} \mathrm{C}, 20 \mathrm{~min} \mathrm{C}_{\mathrm{NaOH}}=0.75 \mathrm{M}\right)$. The reaction order in oxygen concentration ( $c=1.0$ both for syringic aldehyde and vanillin) is assessed by analysis of plot $\ln \left(K_{\mathrm{obs}}\right)$ vs $\ln \left(P_{\mathrm{O}_{2}}\right)$.

$10^{10}$ for SAC) and employing the Eyring equation adapted for the reactions of the first order: ${ }^{27}$

$$
\Delta \mathrm{S}^{\ddagger}=2.303 R(\log A-\log T-10.75)
$$

The difference in $\Delta S^{\ddagger}$ of around $110 \mathrm{~J} \mathrm{~mol}^{-1} \mathrm{~K}^{-1}$ at $423 \mathrm{~K}$ for SA $\left(-158 \mathrm{~J} \mathrm{~mol}^{-1} \mathrm{~K}^{-1}\right)$ and for SAC $\left(-49 \mathrm{~J} \mathrm{~mol}^{-1} \mathrm{~K}^{-1}\right)$ corresponds to entropy difference between uni- and bimolecular reactions thus indicating that SAC should be formed intramolecularly. Among different possible reaction routes, the contribution of alkali-promoted disproportionation reactions to the formation of SAC can be considered. These reactions may be looked upon as pseudo-unimolecular and were suggested already on the basis of the analysis of anaerobic kinetics (Figure 2) and obtained $E_{\text {a }}$ value $(108 \mathrm{~kJ} / \mathrm{mol})$.

On the basis of the kinetic data and general considerations for lignin oxidation pathways in alkaline media the hypothetic reaction scheme of LS oxidation to aromatic aldehydes was proposed (Figure 6). The formation of lignin structures with conjugated double bonds, that are highly reactive with oxygen, occurs via the partial desulfonation of LS under alkaline conditions. ${ }^{6}$ These reactions lead to the formation of $\mathrm{C}_{\alpha}-\mathrm{C}_{\beta}$ unsaturated structures vulnerable to oxidation with oxygen under alkaline conditions. ${ }^{18,24-26,28}$ Pathway B in Figure 6 refers to an oxidative route of aromatic aldehyde formation via the attack 
<smiles>[R]C(C=C1C=C(OC)C(=O)C(OC)=C1C=C(C)[C@H](C)O)CO</smiles><smiles>OCCOCCO</smiles><smiles>[R]C(C=O)=Cc1cc(OC)c(O)c(OCC(C)(C)C(C)(C)C(C)(C)C)c1</smiles>

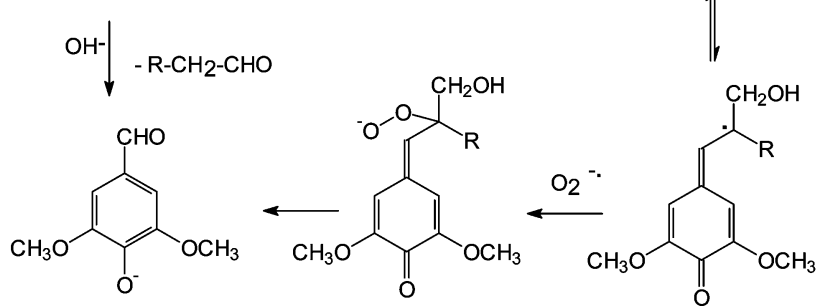

Figure 6. Schematic representation of LS oxidation by oxygen in alkaline medium. LS is presented as phenolic $\alpha$-sulfonated $\mathbf{S}$ unit linked by $\beta-O-4$ bond to neighboring phenyl propane unit $(\mathrm{R}=\mathrm{OAr})$.

of oxygen to one-electron oxidized lignin unit with the formation of hydroperoxide or 1,2-dioxetane derivatives followed by homolytic splitting of $\mathrm{C}_{\alpha}-\mathrm{C}_{\beta}$ bonds in the propane chain. ${ }^{28}$ Pathway A depicts the eventual heterolytic route via retroaldol cleavage of emerged coniferyl/sinapyl aldehyde-type structures. ${ }^{11,12}$ These structures may occur to some extent in nonoxidized original LS thus giving rise the aromatic aldehydes under anaerobic conditions (Figure 2).

Effect of Catalyst. Salts of transition metals are known catalysts in the oxidation of LS to aromatic aldehydes. ${ }^{4,6,9-11,18}$ It is believed that metal cations in the highest oxidation state $\left(\mathrm{Me}^{n+}\right)$ abstract an electron from phenolate via the formation of a transition complex producing the phenoxy radicals:

$$
\mathrm{Me}^{n+}+\mathrm{PhO}^{-} \rightarrow \mathrm{Me}^{(n-1)+}+\mathrm{PhO}^{\cdot}
$$

One-electron oxidized lignin units react subsequently with oxygen giving rise to aromatic aldehydes. Alternatively a homolytic splitting of a $\mathrm{C}_{\alpha}-\mathrm{C}_{\beta}$ bond at high temperature can take place even under an aerobic atmosphere leading to the formation of aromatic aldehydes. ${ }^{6}$ The reoxidation of reduced catalyst $\left(\mathrm{Me}^{(n-1)+}\right)$ by oxygen is a problematic step, and relatively high catalyst-to-substrate ratios are required. However, at the same time, an excess of catalyst $\left(\mathrm{Me}^{n+}\right)$ may affect negatively the yield of aromatic aldehydes due to their overoxidation. $^{15}$

About $20 \%$ (w/w on $\mathrm{LS}$ ) of $\mathrm{CuSO}_{4}$ salt was introduced into the reaction system $\mathrm{O}_{2} / \mathrm{NaOH}\left(150{ }^{\circ} \mathrm{C}, 20 \mathrm{~min}, P_{\mathrm{O}_{2}}=6\right.$ bar, $\left.C_{\mathrm{NaOH}}=0.75 \mathrm{M}\right)$ and compared with noncatalyzed oxidation of PTHSL (Figure 7). The increase of SA and VA yields in the presence of catalyst was about $30 \%$ and $40 \%$, reaching $10.0 \%$ and $3.4 \%$ based on LS weight, respectively. Although the total yield of aromatic aldehydes is roughly double than usually reported for the oxidation of softwood LS to vanillin, $4,6,9-11$ the catalyst effect was rather moderate. It was reported that copper salts used as catalysts improve the selectivity and the yields of aromatic aldehydes to as higher as $100 \% .^{4,6,9-11}$ This
Syringic aldehyde
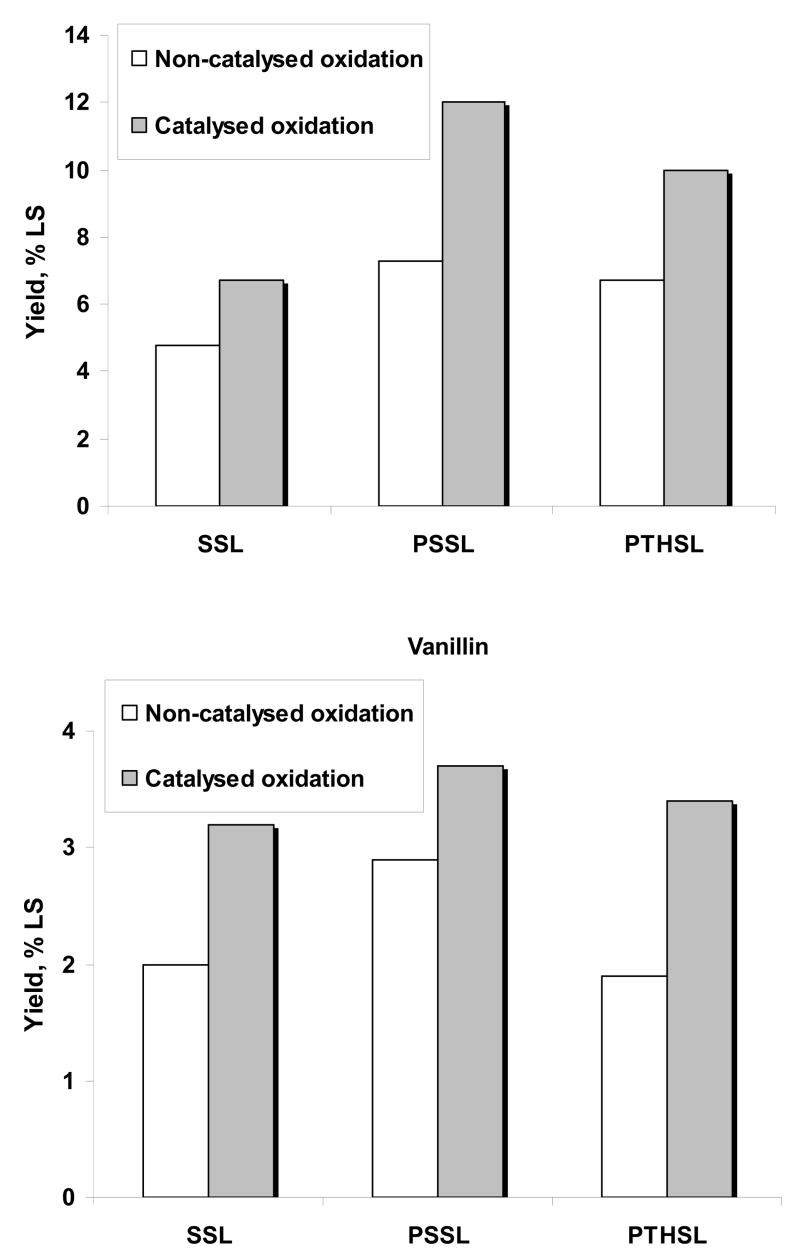

Figure 7. Yields of aromatic aldehydes (average relative error of 7\%) in noncatalyzed and catalyzed with $\mathrm{CuSO}_{4}$ oxidation of three $\mathrm{LS}$ samples with oxygen in $\mathrm{NaOH}$ solution $\left(150{ }^{\circ} \mathrm{C}, 20 \mathrm{~min}, P_{\mathrm{O}_{2}}=6 \mathrm{bar}, \mathrm{C}_{\mathrm{NaOH}}=0.75 \mathrm{M}\right.$, load of $\mathrm{CuSO}_{4}$ is $20 \% \mathrm{w} / \mathrm{w}$ on LS). The chemical compositions of SSL, PSSL, and PTHSL are presented in Table 3.

Table 3. Chemical Composition of LS Samples ${ }^{17}$

\begin{tabular}{cccc}
\hline & \multicolumn{3}{c}{ composition of substrate, \% (w/w) } \\
\cline { 2 - 4 } liquor sample $\left(M_{\mathrm{w}}, \mathrm{Da}\right)^{a}$ & lignosulfonates & $\begin{array}{c}\text { inorganic salts } \\
\text { and phenolic } \\
\text { extractives }\end{array}$ \\
\hline SSL (950) & 55 & 27 & 18 \\
PSSL (2400) & 89 & 5 & 6 \\
PTHSL (1250) & 84 & 8 & 8
\end{tabular}

${ }^{a}$ Designation for LS samples is given in the text. ${ }^{b}$ Mainly xylose.

fact may be explained by the presence of reducing sugars in PTHSL that react with $\mathrm{Cu}^{2+}$ thus consuming the active catalyst species:

$$
\mathrm{R}-\mathrm{CHO}+2 \mathrm{Cu}^{2+} \rightarrow 2 \mathrm{Cu}^{+}+\mathrm{R}-\mathrm{COOH}
$$

To verify this proposition a series of LS were prepared via sulfite liquor purification by dialysis using membranes of different pore size. The sulfite liquor was freeze-dried without purification (SSL sample) and was purified by dialysis with a cellophane membrane of 5000 NMWCO. This allowed a PSSL sample with low sugar content but a higher molecular weight of LS than that in SSL due to the partial elimination of the low molecular weight fraction. ${ }^{17}$ The general chemical composition of LS samples is presented in Table 3. 
Effect of Concomitants on the Oxidation of Lignosulfonates. The oxidation of nonpurified (SSL) and purified (PSSL) LS samples revealed a clear dependence between the yields of SA and VA and the residual sugars content (Table 3, Figure 7). This was especially notable for the oxidation catalyzed by copper salt. The SA yield was increased almost twice while the amount of residual sugars in the LS sample diminished (comparing SSL and PSSL). The PTHSL, containing an intermediate amount of residual sugars between SSL and PSSL, showed intermediate yields of SA and VA (Figure 7). If in the catalytic oxidation the negative effect of sugars may be explained by the competition between LS and sugars in reaction with the catalyst, in the noncatalyzed oxidation sugars can compete with LS in the consumption of reagents (oxygen and alkalinity). However, some specific interactions between sugars and reaction products cannot be completely excluded. For example, it was suggested using model compounds, that benzaldehyde structures reacts with reducing sugars via aldol condensation mechanisms under alkaline conditions giving rise the adducts with carbon-carbon linkages between sugar residues and aromatic ring. ${ }^{29}$ Hence sugars can affect the yield of aromatic aldehydes via base-promoted reactions.

The average molecular weight of LS in PSSL was more than twice that in SSL (Table 3). It may be expected that the molecular weight negatively affects the yield of aromatic aldehydes from LS upon oxidation with oxygen due to lower amounts of phenolic structures, but this was not the case of PSSL that gave higher yields of SA and VA than SSL (Figure 7). Unlike PSSL, which does not possess monomeric LS, SSL contained more than $20 \%$ (w/w) of monomeric 4-allyl-phenyl$\alpha$-sulfonic acid-type structures ${ }^{17}$ that are considered precursors of $\left(\mathrm{OCH}_{3}\right)_{n} \mathrm{PhCH}(\mathrm{OH}) \mathrm{CH}(\mathrm{R}) \mathrm{CHO}$ type structures giving rise to SA $(n=2)$ and VA $(n=1)$ in reactions of retro-aldol cleavage under strong alkaline conditions. ${ }^{6,11,14}$ These kinds of reactions, however, were apparently not decisively important under applied conditions, because the yields of SA and VA were significantly lower in the case of SSL oxidation than in the oxidation of PSSL.

The maximal yields of SA (11.0\%) and VA $(2.5 \%)$ in noncatalyzed oxidation of PTHSL were obtained at $150{ }^{\circ} \mathrm{C}$ for $20 \mathrm{~min}$ in $0.9 \mathrm{M}$ alkaline solution and oxygen pressure of 10 bar. Under the same conditions in the presence of catalyst $(20 \%$ w/w on LS) the yields of SA and VA were $16.1 \%$ and $4.5 \%$, respectively. These results evidence a high potential of eucalypt LS for the production of syringic aldehyde and vanillin. Taking into consideration that about $350-400 \mathrm{~kg}$ of LS is formed per 1 ton of produced eucalypt cellulosic pulp, the theoretical yield of aromatic aldehydes may reach up to $80 \mathrm{~kg}$ per ton of absolutely dried pulp. Assuming the average price of aromatic aldehydes as roughly $10 \mathrm{USD} / \mathrm{kg},{ }^{5}$ the results obtained correspond to gross profits of ca. $800 \mathrm{USD} /$ ton of pulp, which is almost twice of the average market price for sulfite eucalypt pulp.

\section{Conclusions}

Oxidation of eucalypt lignosulfonates (LS) by molecular oxygen in alkaline medium leads to a predominant formation of syringic aldehyde (SA) and vanillin (VA) among low molecular weight aromatic oxidation products. According to kinetic results the rate constant of SA formation was more than twice of that for VA. At the same time, SA suffered faster degradation (about 5 times) than VA under the same conditions of LS oxidation. Hence the maxima yields of these aromatic aldehydes are not coincident, and their proportions in a reaction mixture may vary significantly. These features must be considered while optimizing the conditions of LS oxidation into desired aromatic aldehydes.

The oxidation reactions involving homolytic splitting of $\mathrm{C}_{\alpha}-\mathrm{C}_{\beta}$ bonds in phenyl propane units contribute to major amounts of aromatic aldehydes rather than base-promoted heterolytic reactions (retro-aldol cleavage of $\mathrm{C}_{\alpha}-\mathrm{C}_{\beta}$ bonds). The contribution of monomeric 4-allyl-phenyl- $\alpha$-sulfonic acid-type structures into aromatic aldehydes via retro-aldol cleavage of $\mathrm{C}_{\alpha}-\mathrm{C}_{\beta}$ bonds was lower than expected and may be explained by the non-coincident optimal conditions for the oxidative and alkali-promoted reactions. This requires further investigation. It was proposed that aromatic acids in LS oxidation under alkaline conditions are formed via different mechanisms than aromatic aldehydes. At least part of the aromatic acids emerge as the result of base-induced disproportionation reactions of corresponding aldehydes.

The addition of copper salt as a catalyst ( $20 \% \mathrm{w} / \mathrm{w}$ on LS) promoted the increment of aromatic aldehyde yields by $25-50 \%$ upon oxidation. The total yield of SA (16.1\%) and VA (4.5\%) was higher than $20 \%$ and obtained from the eucalypt LS oxidation at $150{ }^{\circ} \mathrm{C}$ for $20 \mathrm{~min}$ in $0.9 \mathrm{M}$ alkaline solution and oxygen pressure of $10 \mathrm{bar}$. These results showed a potential of eucalypt LS for the production of aromatic aldehydes. The concomitant carbohydrates affect drastically the yields of aromatic aldehydes and should be eliminated from sulfite spent liquor before the LS oxidation.

\section{Acknowledgment}

Authors thank the Portuguese Innovation Agency (ADI) for the financial support of this work carried out in the frame of the FEDER/PRIME Program (Grant SIME No. 00/22689) and Portuguese Foundation for Science and Technology for the Ph.D. grant of Ana P. Marques (SFRH/BD/31463/2006).

Supporting Information Available: Figure 1 listing of the fragment of total ion chromatogram of oxidation products from LS oxidation $\left(160{ }^{\circ} \mathrm{C}\right.$; reaction time of $15 \mathrm{~min}$; PTHSL concentration of $1.0 \% ; C_{\mathrm{NaOH}}=0.75 \mathrm{M}$; oxygen pressure 6 bar). Figure 2A shows a typical electropherogram of products in oxidate after LS oxidation. Figure 3A depicts the typical plot $\ln \left(\left[\mathrm{P}_{\infty}\right]-[\mathrm{P}]\right)$ vs $t$ used for the determination of $K_{\text {obs }}$ in the oxidation of LS to SA (temperature $=140{ }^{\circ} \mathrm{C}$, Table 2). This material is available free of charge via the Internet at http:// pubs.acs.org.

\section{Literature Cited}

(1) Casey, J. P. Pulp and Paper. Chemistry and Chemical Technology; John Wiley \& Sons: New York, 1980.

(2) Hoyt, C. H.; Goheen, D. W. Polymeric products. In Lignins Occurrence, Formation, Structure and Reactions; Sarkanen, K. V., Ludwig, C. H., Eds.; Wiley Interscience: New York, 1971; p 833.

(3) Busch, R.; Hirth, T.; Liese, A.; Nordhoff, S.; Puls, J.; Pulz, O.; Sell, D.; Syldatk, C.; Ulber, R. The utilization of renewable resources in German industrial production. Biotechnol. J. 2006, 1, 770.

(4) Bjørsvik, H.-R. Fine chemicals from lignosulfonates. 1. Synthesis of vanillin by oxidation of lignosulfonates. Org. Process Res. Dev. 1999, 3,330 .

(5) Hocking, M. B. Vanillin: synthetic flavoring from spent sulfite liquor. J. Chem. Educ. 1997, 74 (9), 1055.

(6) Goheen, D. W. Low molecular weight chemicals. In Lignins Occurrence, Formation, Structure and Reactions; Sarkanen, K. V., Ludwig, C. H., Eds.; Wiley Interscience: New York, 1971; p 797.

(7) Bjørsvik, H.-R.; Liguori, L. Organic processes to pharmaceutical chemicals based on fine chemicals from lignosulfonates. Org. Process Res. Dev. 2002, 6, 279. 
(8) Sazanov, Yu. N.; Podeshvo, I. V.; Mikhailov, G. M.; Fedorova, G. N.; Goikhman, M. Ya.; Lebedeva, M. F.; Kudryavtsev, V. V. Polymeric materials derived from vanillic acid. Russ. J. Appl. Chem. (Engl. Transl.) 2002, 75 (5), 777 .

(9) Bogomolov, B. J.; Sapotnitsky, S. A. Processing of Sulfate and Sulfite Liquors (in Russian); Lesnaya Prom.: Moscow, USSR, 1989.

(10) Kuznetsov, B. N.; Kuznetsova, S. A.; Danilov, V. G.; Kozlov, I. A.; Taraban'ko, V. E.; Ivanchenko, N. M.; Alexandrova, N. B. New catalytic processes for a sustainable chemistry of cellulose production from wood biomass. Catal. Today 2002, 75, 211.

(11) Tarabanko, V. E.; Petukhov, D. V.; Selyutin, G. E. New mechanism for the catalytic oxidation of lignin to vanillin. Kinet. Catal. 2004, 45, 569 (translation from Kinet. Katal.).

(12) Tomlinson, G. H.; Hibbert, H. Studies on Lignin. XXIV. The Formation of Vanillin from Waste Sulfite Liquor. J. Am. Chem. Soc. 1936, 58,345 .

(13) Kratzl, K.; Spona, J. Über den mechanismus der alkalischen hydrolyse von guajacylglyzerin- $\beta$-aryläther- $\alpha$-sulfosäure II. Mitteilung. Synthese der guajacylglyzerin- $\beta$-guajacyläther- $\alpha$-sulfosäure- $\gamma-{ }^{14} \mathrm{C}$ und deren alkalische hydrolyse. Holzforschung 1966, 20, 27.

(14) Tarabanko, V. E.; Petukhov, D. V. Study on mechanism and improvement of the process of oxidative cleavage of lignins into the aromatic aldehydes. Chem. Sustainable Dev. 2003, 11, 655.

(15) Dardelet, S.; Froment, P.; Lacoste, N.; Robert, A. Vanilline et aldéhyde syringique: stabilité à l'oxydation en milieu alcalin par l'oxygène. Rev. ATIP 1985, 39, 369.

(16) Marques, A. P.; Evtuguin, D. V.; Magina, S.; Prates, A. Chemical composition of spent liquors from acidic magnesium-based sulfite pulping of eucalyptus globulus. J. Wood Chem. Technol. 2009, 29, 322.

(17) Marques, A. P.; Evtuguin, D. V.; Magina, S.; Amado, F.; Prates, A. Structure of lignosulphonates from acidic magnesium-based sulfite pulping of eucalyptus globulus. J. Wood Chem. Technol. 2009, 29, 337.

(18) Dardelet, S.; Froment, P.; Lacoste, N.; Robert, A. Aldehyde syringique. Possibilite de production a partir de bois feuillus. Rev. ATIP 1985, 39, 267.
(19) Fargues, C.; Mathias, A. L.; Rodrigues, A. E. Kinetics of vanillin production from kraft lignin oxidation. Ind. Eng. Chem. Res. 1996, 35, 28.

(20) Sales, F. G.; Abreu, C. A. M.; Pereira, J. A. F. R. Catalytic wet-air oxidation of lignin in a three-phase reactor with aromatic aldehyde production. Braz. J. Chem. Eng 2004, 21 (2), 211.

(21) Wallick, S. A.; Sarkanen, K. V. Effect of $\mathrm{pH}$ on the autoxidation kinetics of vanillin. Wood Sci. Tecnol. 1983, 17, 107.

(22) Fargues, C.; Mathias, A. L.; Silva, J.; Rodrigues, A. E. Kinetics of vanillin oxidation. Chem. Eng. Technol. 1996, 19, 127.

(23) Ian, C.; Watt, F. Hydride shifts and transfers. In: Advances in Physical Organic Chemistry; Academic Press: New York, 1988; Vol. 24, p 81 .

(24) Starnes, W. H. Mechanisms of autoxidation in neutral or alkaline media. In Chemistry of Delignification with Oxygen, Ozone and Peroxides, Gratzl, J. S., Nakano, J., Singh, R. P., Eds.; Uni Publishers Co., Ltd.: Tokyo, Japan, 1980; p 3.

(25) Shevchenko, S. M. Oxidation of lignin. In Advances in Oxygenated Processes; Baumstark, A. L., Ed.; JAI Press Inc.: New York, 1995; Vol. 4, p 131.

(26) Ji, Y.; Vanska, E.; van Heiningen, A. Rate determining step and kinetics of oxygen delignification. Pulp Pap. Can. 2009, 110, 29.

(27) Schmid, R.; Sapunov, V. N. Non-formal Kinetics: In Search for Chemical Reaction Pathways; Verlag Chemie: Weinheim, Germany, 1982.

(28) Gierer, J. The chemistry of delignification. A general concept. Part II. Holzforschung 1982, 36, 55 .

(29) Gierer, J.; Wännström, S. Formation of alkali-stable C-C-bonds between lignin and carbohydrate fragments during kraft pulping. Holzforschung 1984, 38, 181 .

Received for review July 1, 2010 Revised manuscript received October 25, 2010 Accepted November 5, 2010 